therapy by measurement of white blood cell, lymphocyte, T/B cell, CD4 and CD8 T cell counts. The CD 4/8 ratio, lymphocyte blastoid transformation, and levels of IgA, IgM, and $\mathrm{IgG}$ were also measured before, immediately after, and at 1, 3,6, and 12 months after ACTH therapy. Cortrosyn Z, a synthetic analogue of ACTH, was administered at a relatively low dosage between $0.015 \mathrm{mg} / \mathrm{kg} /$ day and $0.00625 \mathrm{mg} / \mathrm{kg} / \mathrm{day}$. Lymphocyte counts and CD4 T cell levels were significantly decreased immediately after and at 1 and 3 months after therapy, and they returned to normal but not pretreatment levels at 6 and 12 months. Helper $\mathrm{T}$ cells were more depressed than cytotoxic $\mathrm{T}$ cells, but immunoglobulin levels did not change after ACTH therapy. (Ohya T, Nagai T, Araki Y, et al. A pilot study on the changes in immunity after ACTH therapy in patients with West syndrome. Brain Dev Dec 2009;31:739-743). (Respond: Dr T Matsuishi. E-mail: tmatsu@med.kurume-u.ac.jp).

COMMENT. Lymphocyte and $\mathrm{T}$ cell counts are significantly decreased immediately after and at 1 and 3 months after ACTH therapy, and then gradually recover. A delay of vaccinations for 6 months after ACTH therapy, as practiced by 55\% of pediatricians in Japan, is justified based on the results of this study. The authors point out that cell counts used are not direct measures of the actual immunological response. Rather, they indirectly reflect the ability of the individual patient to produce antibodies with vaccinations.

\title{
FOCALITY AND HETEROGENEITY OF FEBRILE SEIZURES
}

The semiology of febrile seizures (FS), their focality, relation to hippocampal damage, and heterogeneous origin are critically reviewed by researchers at the Institute of Child Health, and Great Ormond Street Hospital, London, UK. Early semiology, the most important clue to focal origin, has been neglected. Aural features have temporal lobe characteristics consisting of fear and lip smacking, and rare motor manifestations. FS arise in the hippocampus with transient and mild temporal lobe features and rapid spread to neocortex. FS include an unknown proportion of non-epileptic reflex and asystolic attacks. The definition of FS with fever not directly involving the nervous system may need to be modified by possible direct cerebral toxin involvement eg Shigella, HHV6 and malaria infections. The early seizure semiology should be used to separate the various seizures included as FS and to determine whether atypical FS such as Dravet syndrome and generalized epilepsy with FS plus have similar focal/temporal lobe features. (Neville BGR, Gindner D. Febrile seizures-semiology in humans and animal models: evidence of focality and heterogeneity. Brain Dev Jan 2010;32:33-36). (Respond: Dr Brian GR Neville. E-mail: B.Neville@ich.ucl.ac.uk).

COMMENT. Drs Neville and Ginder emphasize the importance of early seizure semiology in our understanding of the FS origin, and refer to the FS as a "specific epilepsy syndrome." Investigators have debated the definition of FSs and their relation to epilepsy for more than a century. Is a FS a distinct disease entity or a form of epilepsy? The early literature was divided between those who favor the former or the latter definition. WG Lennox (1953) used the terms "mild" and "pure" forms of epilepsy, whereas Livingston (1954) reverted to the older concept of a specific entity, the "simple 
febrile convulsion," distinct from the epilepsies. (Millichap JG. Definition of febrile seizures. In: Febrile Seizures ed Nelson KB, Ellenberg JH, New York; Raven Press, 1981;1-3). Genetic studies show that inheritance of FS is polygenic with no significant differences between simple and complex FS patients. The cytokine gene ILIB-511 is associated with sporadic but not familial simple FS. Cytokine genes may act as enhancers or attenuators of FS susceptibility. Genetic association studies may lead to a better understanding of the molecular basis of FS and the relation to epilepsy. (Kira R et al. Genetic susceptibility to febrile seizures. Brain Dev Jan 2010;32:57-63).

\section{PERIPHERAL NEUROPATHIES}

\section{PHARMACOKINETICS OF INTRAVENOUS IMMUNOGLOBULIN AND OUTCOME OF GUILLAIN-BARRE SYNDROME}

The relation of pharmacokinetics of intravenous immunoglobulin (IVIg) to the outcome of Guillain-Barre syndrome (GBS) was determined in 174 adults treated at Erasmus Medical Center, Rotterdam, The Netherlands. All patients were unable to walk unaided and all received the standard dose IVIg, $0.4 \mathrm{~g} / \mathrm{kg} / \mathrm{body}$ weight $/$ per day for 5 consecutive days (total $2 \mathrm{~g} / \mathrm{kg} /$ body weight), within 2 weeks of onset of weakness. Total IgG levels in serum samples obtained immediately before and 2 weeks after the start of IVIg administration were determined by turbidimetry and related to clinical outcome at 6 months. The increase in serum IgG 2 weeks after IVIg varied widely between patients (mean $7.8 \mathrm{~g} / \mathrm{L}, \mathrm{SD} 5.6 \mathrm{~g} / \mathrm{L}$ ). Patients with a low $\mathrm{IgG}$ recovered significantly more slowly, and fewer could walk unaided at 6 months $(\mathrm{p}<0.001)$. The association of low $\mathrm{IgG}$ with poor outcome was independent of other known prognostic factors $(\mathrm{p}=0.022)$. Patients with a small increase in serum IgG may benefit from a higher dosage or second course of IVIg. (Kuitwaard K, de Gelder J, Tio-Gillen AP, et al. Pharmacokinetics of intravenous immunoglobulin and outcome in Guillain-Barre syndrome. Ann Neurol Nov 2009;66:597-603). (Respond: Dr K Kuitwaard, Department of Neurology, Room H 673, Erasmus Medical Center, PO Box 2040, 3000 CA Rotterdam, The Netherlands. E-mail: k.kuitwaard@erasmusmc.nl).

COMMENT. The high variability of IVIg pharmacokinetics in patients with GBS is related to clinical course and outcome. Monitoring the serum IgG levels may optimize the use of IVIg treatment in individual GBS patients.

In an editorial, Cornblath DR and Hughes RAC (Ann Neurol 2009;66:569-570) comment that despite the benefits of treatment of GBS with IVIg or plasma exchange, 2$3 \%$ of patients with severe GBS die within 1 year and $15-18 \%$ have significant disability. The IVIg dose was chosen based initially on studies in idiopathic thrombocytopenia, and higher doses or longer courses have not been properly evaluated in GBS. Furthermore, not all cases are acute inflammatory demyelinating polyneuropathy. Some cases are acute motor axonal neuropathy and Fisher's syndrome that may respond differently. Controlled clinical trials show benefit of IVIg in CIDP, GBS, and multifocal neuropathy. Trials of IVIg in different doses and duration are also indicated in other diseases. 